\title{
ENTRE O CAOS E O PORVIR: UMA LEITURA TRANSVERSAL DO PENSAMENTO DE NIETZSCHE
}

\author{
Adilson Felicio Feiler ${ }^{1}$ \\ Universidade do Vale do Rio dos Sinos (UNISINOS) \\ https://orcid.org/0000-0001-7352-927X
}

\begin{abstract}
RESUMO:
A atualidade da pesquisa Nietzsche se mostra como um fator importante para se pensar sobre o futuro de instituições sociais assentadas sobre regras dogmáticas. Para além dos grandes sistemas mostra-se o caos, implantado pelo niilismo, e frente ao qual se desenha o porvir de uma nova aurora. No entanto, cabe a pergunta pelo alcance desta aurora do porvir; em que medida esta é capaz de trazer otimismo diante do turbilhão niilista. Estas páginas pretendem trazer algumas pistas para se refletir sobre este paradoxo do pessimismo do caos niilista e do otimismo do porvir. Para tanto se procede a uma leitura transversal de Nietzsche, do estado atual, passando pela sua crítica para culminar em seu futuro.
\end{abstract}

PALAVRAS-CHAVE: Nietzsche; Niilismo; Porvir; Otimismo.

\section{BETWEEN THE CHAOS AND FOR COMING: A CROSS-READING OF NIETZSCHE'S THOUGHT}

\begin{abstract}
:
The presente Nietzsche research show itself as an important factor to thing about the future of the socials institutions based about the dogmatic rules. Beyond of big sistems it shows the chaos, implanted by the nihilism, and front which draws the future of the dawning. However, falls the question by the scope of this dawning of the future; to extend to whitch it is able of bring optimismin the presence of nihilistic whirl. These pages intend bring some track to reflect about the paradox of the pessimismo of nihilistic chaos and the optimism of future. For both proceeds to a transversal lecture of Nietzsche, from the current state, passing by the critic, to culminate in its future.
\end{abstract}

\footnotetext{
${ }^{1}$ Doutor em Filosofia pela Pontifícia Universidade Católica do Rio Grande do Sul (PUCRS), Rio Grande Sul - Brasil. Professor da Universidade do Vale do Rio dos Sinos (UNISINOS), Rio Grande do Sul - Brasil. E-mail: feilersj@yahoo.com.br
} 
KEYWORDS: Nietzsche; Nihilism; Future; Optimism.

\section{Considerações iniciais}

"É preciso ter o caos dentro de si para dar à luz uma estrela cintilante." (NIETZSCHE, AFZ, I Preâmbulo, n. V). O pensamento de Nietzsche esteve durante muito tempo associado a uma concepção desconstrutivista da verdade da razão, da moral e da religião. Diante de tal posição nada se constrói, pois tudo se apresenta como lançado num campo agonístico, de lutas entre forças que, continuamente se entrecruzam. São adeptos desta posição autores como Frederic Copleston, Scarlett Marton ${ }^{2}$. Contudo, essa visão iconoclasta de Nietzsche já dá espaço a uma nova posição que é aquela denominada construtiva, na qual é possível apresentar uma ética no seu pensamento. São defensores desta posição autores como Paul Valadier e Oswaldo Giacóia ${ }^{3}$.

Retornando àquela citação de Nietzsche, enunciada no princípio desta Introdução, de que o caos é necessário como momento que antecede a construção, representada pelo brilho da estrela temos a impressão de que Nietzsche está operando na lógica do Cristianismo ascético, pois apresenta uma proposta de vida baseada no esvaziamento de si para deste esvaziamento poder ascender à promessa de vida eterna. Eis, portanto, o que tal citação evoca: uma promessa, um porvir, para além do caos e de toda a desconstrução. Ora, o pensamento de Nietzsche, contudo, revela-se marcado por referências cristãs, e, por mais que este julgue ser o Cristianismo algo do qual já não faz mais sentido falar, como quando ele se refere no Anticristo afirmando que "existiu apenas um cristão, e este morreu na cruz." "Este mesmo Cristianismo percorre todas as vias de seu pensamento. Por essa razão, é possível apostar em duas propostas. A primeira delas é a do Cristianismo como um conjunto de leis, regras, doutrinas; a segunda como uma proposta existencial, de uma experiência. Diante destas duas propostas somos incitados a apostar no fato de que Nietzsche tenha lutado em toda a sua vida contra aquele modelo de Cristianismo evocado na primeira proposta, o Cristianismo moral, típico de sua educação pautada pelo ambiente do pietismo protestante. Disso são provas, inclusive, diversas referências depreciativas com relação a Lutero. E, dado que nas palavras de

\footnotetext{
${ }^{2}$ Marton reluta em ver na filosofia de Nietzche uma proposta ética, no entanto considera que "[...] seu pensamento apresenta-se como um sistema em aforismos. Tanto é assim que nele se encontram uma filosofia da natureza, uma filosofia do espírito e uma teoria do conhecimento estreitamente relacionadas" (MARTON, 1990, p. 23).

${ }^{3}$ Como lembra Oswaldo Giacoia Júnior, é justamente na "[...] dissolução da unidade substancial da alma" ${ }^{3}$ que a proposta Nietzschiana se levanta como "[...] um dos principais efeitos de sua crítica da moral, da religião e da metafísica." (GIACOIA JÚNIOR, 2001, p. 25).

${ }^{4}$ Cf. NIETZSCHE, Anticristo, KSA, § 39, 1999, p. 211
} 
Nietzsche há uma referência constante ao Cristianismo, percebemos que por mais que este queira dele distanciar-se dele, ou até mesmo, negar, este se torna um projeto impossível, pois este está sempre presente em suas incursões. Isso parece soar como contrassenso debater-se com algo pelo qual este permanece, constantemente, um sem horizonte. Por isso, somos levados a associar o pensamento de Nietzsche àquela segunda proposta acima evocada, segundo a qual Nietzsche constantemente traz o Cristianismo em suas referências, por considerar que o Cristianismo é, acima de tudo, uma prática, tal como ele explicitamente refere no Anticristo. Nossa proposta é a de apresentar, de maneira provocativa: por que ainda estudar Nietzsche? o que pode ser importante neste autor para se pensar as grandes questões que hoje são postas? Para tanto, principiamos nosso debate com uma descrição fenomênica sobre o estado atual da pesquisa Nietzsche no Brasil e no mundo. Em seguida apresentamos uma crítica sobre a forma pela qual o pensamento de Nietzsche tem sido recepcionado e finalmente, fazermos um balanço sobre o presente e o futuro dos estudos Nietzsche.

\section{A fenomenologia: uma descrição sobre o estado atual da pesquisa Nietzsche}

Os arquivos Nietzsche, localizados em Weimar, na Alemanha estão abertos à visitação de pesquisadores de todo o mundo. Recentemente, inclusive, foi publicado mais um volume na Edição Crítica de Nietzsche, organizada por Górgio Colli e Mazzino Montinari, fazendo assim, com que a pesquisa Nietzsche continue evoluindo. Chama a atenção o fato de que entre Colli, mestre de Montinari, sempre houve uma posição antípoda em termos de pensamento; no entanto, a pesar disso, em ambos, atua uma sinergia que resulta numa perfeita síntese. Segundo Colli, por faltar o componente intuitivo e dedutivo, não se dá para dizer ao certo quando o dito de Nietzsche é falso ou verdadeiro. Montinari diz que o mundo de Nietzsche é o mundo de seus acontecimentos e experiências.

Ha dois anos, no Congresso Interamericano de Filosofia, sediado na cidade de Salvador, o professor Oswaldo Giacoia organizou uma mesa de debate sobre o tema do estado atual da pesquisa Nietzsche no Brasil e no mundo. A professora Scarlett Marton, que havia sido convidada a fazer parte desta mesa, apresentou três possíveis leituras que hoje realizadas sobre o pensamento de Nietzsche. Uma primeira é a leitura dogmática, que se estriba exclusivamente sobre a letra dos textos de Nietzsche. A segunda é a leitura instrumental dos textos de Nietzsche, que se serve da leitura de Nietsche como uma caixa de ferramentas para pensar os mais variados temas. Há, finalmente, uma terceira leitura denominada transgressiva, incluindo na leitura de Nietzsche problemas que são alheios ao seu foco de interesse. Segundo a professora Scarlett, as duas primeiras leituras são admissíveis, contudo não a terceira, pois não auxilia em nada na pesquisa Nietzsche no sentido de desmistificar o seu pensamento. 
Quando a professora Scarlett cita esta terceira via nos estudos de Nietzsche refere-se, de maneira particular, aos pesquisadores nietzschianos anglo-saxãos. Segundo ela, eles conseguem conectar muito bem vários autores, contudo, tal atitude compromete um efetivo aprofundamento sobre um determinado autor. Diante disso, de acordo com a leitura da professora Scarlett, esta terceira via tem ganhado muito campo ultimamente, de modo que diversos pesquisadores, inclusive brasileiros, tem-se deixado fascinar pelo trabalho que autores anglo-saxãos têm realizado no que tange ao pensamento de Nietzsche. Conclui-se que estarmos diante de uma ameaça quanto ao trabalho efetivo de aprofundamento e clarificação do pensamento de Nietzsche. O autor passa a ser objeto de consumo, razão pela qual se diz dele aquilo que se quer. Bem, concordamos com a Professora Scarlett quanto a esse "modismo Nietzsche" que a tantos seduz de maneira desordenada, e que, por isso, faz-se necessário um ordenamento guiado pelo mergulho na escrita de Nietzsche. Contudo, manifestamos uma posição de repúdio a uma posição que facilmente pode levar a um grande afã aos estudos de Nietzsche: a tendência de tornar os seus ditos um dogma de fé. Isso, além de conduzir ao lado oposto daquilo que teria sido o projeto nietzschiano, cria uma disposição acrítica e, por isso, pouco acadêmica.

Ultimamente, o que assistimos no panorama nacional e mesmo mundial é um interesse bastante grande quanto à pesquisa das obras de Nietzsche. Disso são prova os inúmeros trabalhos sobre o autor que têm sido apresentados nos Encontros Nacionais da ANPOF, por exemplo. Assim, como também os inúmeros livros, artigos e periódicos que têm tratado direta ou indiretamente sobre o mesmo. O número dos interessados na pesquisa Nietzsche tem crescido nos últimos dez anos o que nos faz perguntar o porquê de tal fenômeno. Como que um autor, como Nietzsche, com uma estilística difícil e, ao mesmo tempo, bela, avesso a toda e qualquer tentativa de sistematização, mas, ao mesmo tempo, com ingente busca de abarcar o maior número dos grandes temas e problemas, pode continuar despertando tamanho interesse? O próprio Nietzsche, a esse respeito, se expressa dizendo que seus escritos não são destinados para todos. Talvez ele diga isso por manter-se firme quanto à luta contra a moral gregária e, também, pelo fato de que, em mão erradas, seus escritos podem constituir uma bomba mortífera. Desse último ponto é prova uma citação do próprio Nietzsche, quando diz que "eu não sou homem, e sim uma dinamite", Nietzsche pelos nazistas. Isso foi, inclusive, fruto de uma interpolação em seus escritos pela sua irmã Elisabeth Forster, erro somente identificado e corrigido por ocasião da constituição da primeira edição crítica das obras de Nietzsche, realizado por Karl Schlechta.

\footnotetext{
${ }^{5}$ Cf. NIETZSCHE, Ecce Homo, Por que sou um destino, KSA, 1,5, 1999, p. 365
} 
Diante do panorama atual, que ainda respira a influência nietzschiana, somos levados a apresentar algumas razões dos tempos em que vivemos que buscam encontrar, em Nietzsche, alguma resposta para as suas inquietações.

\section{A crítica: a recepção do pensamento de Nietzsche}

Há duas semanas tive a oportunidade de participar do Encontro Anual do Grupo de Estudos Nietzsche (GEN) na UNICAP, em Recife. Em uma das mesas redondas, o Professor Ivo da Silva Júnior da UNESP, falando sobre a recepção de Nietzsche no Brasil, informou que está constituindo na UNESP um Grupo de Estudos destinado a pesquisar a recepção de Nietzsche no Brasil. Consideramos esta uma grande iniciativa, pois vem apontar elementos históricos e culturais que se foram apegando à pesquisa de Nietzsche no Brasil. O grande desafio é o de em que medida é possível tomar um aspecto separado (isolado) do pensamento de Nietzsche a fim de responder às inquietações do ser humano? Por isso, a recepção de Nietzsche foi se dando com o fim de responder a estas inúmeras inquietações, acontecendo uma apropriação do pensamento de Nietzsche de acordo com os seus interesses pessoais, o que facilmente vem a incorrer em interpolações e, até, desvirtuamentos em torno ao seu pensamento. Essa tendência é quase que natural, já que fatores sociais, políticos e culturais têm agido de maneira indelével quanto à recepção do pensamento de Nietzsche, o que tem incorrido em prejuízo de fazer com que a pesquisa em torno ao seu pensamento avançasse. Só para citar, no Brasil, a primeira recepção de Nietzsche da qual se tem notícia, aconteceu no Recife em 1893 por Tobias Barreto. Este entrou em contato com a literatura do jovem Nietzsche basicamente pela linguagem, tanto que o considera arauto do rigor linguístico. O germanista Tobias Barreto, nesta primeira publicação que faz de Nietzsche, o julga como alguém considerado subversivo da ordem moral. De 1893 em diante muitos outros textos passam a ser veiculados na imprensa brasileira.

Ao falarmos da recepção do pensamento de Nietzsche, é conveniente recordar as três grandes tendências que se desdobraram de suas intuições fundamentais. Uma primeira destas tendências, e que tem sua força ainda hoje, é o existencialismo. Esta corrente de pensamento tem como base o fato de que a existência precede a essência. Neste sentido, temos uma desconstrução da metafísica, cujo fundamento é o ser, uma realidade externa ao sujeito. Ora, para o existencialismo o que importa é o ser humano enquanto vive e, nesta vivência, vai tecendo um existir, independente de algum fundamento externo. Ao apresentar o humano, demasiado humano, como fundamento de seu filosofar, Nietzsche parece operar um retorno à corrente que antecede a Sócrates, os sofistas, precisamente em Protágoras, que enuncia o homem como medida do todas as coisas. Esse homem como 
medida de tudo é em Nietzsche aquele que se superou, o além do homem; o Espírito Livre, aquele que faz de sua existência o mote de sua vida, e cuja afirmação é o princípio fundamental da filosofia de Nietzsche. Nas palavras de Paul Valadier a "[...] afirmação e oposição são vigorosamente opostas uma frente a outra e essas não são apenas alternativas vazias. Mais precisamente, a base de sua posição provém da oposição que se obtém a respeito da realidade que Nietzsche, equivocadamente, chama o todo - vida, existência."

Desta inspiração nietzschiana existencialista, surgiram duas grandes correntes inspiradas nesta tendência: a) o existencialismo cristão, liderado por Kierkegaard, considerado por muitos como o maior crítico do Cristianismo, maior que o próprio Nietzsche, pois centra o valor do Cristianismo em sua cristicidade, em sua prática; e b) o existencialismo ateu, liderado por Sartre, de modo que a própria liberdade é compreendida como condenação de um ser lançado num mundo sem Deus.

A segunda grande tendência que tem sido inspirada pelo pensamento nietzschiano é a psicanálise com sua expressão principal em Freud. Segundo este, Nietzsche é aquele que mais profundamente conheceu-se a si mesmo. Pois a psicanálise trata do ser humano compreendido como aquele é um "poço caótico". E, é com esta multiplicidade de cacos, resultantes de uma existência humana esfacetada, que a clínica o tematiza pelo acento na palavra que Freud vai revolucionar a maneira pela qual a psique humana foi tratada. Pela palavra emitida pelo paciente, o psicanalista vai estabelecendo chaves de interpretação que revelam o conteúdo inconsciente deste, tal como também ocorre com os atos falhos e o sonho. Desse modo, o organismo psíquico não possui nenhum objetivo a atingir; apenas interpretar, no constante movimento da vida, que é um eterno retorno. No eterno retorno, como recorda Oswaldo Giacoia Júnior, o eterno se presentifica conferindo a mais dura realidade a ser enfrentada: "[...] o amor do destino (amor fati) 7 ", a acolhida do momento culminante da força. Logo, o conteúdo psíquico inconsciente revelado na clínica psicanalítica não é verdade, senão interpretação, que em seu eterno retorno vai perfazendo inúmeros epiciclos.

Desta segunda tendência decorre ainda uma terceira que é a filosofia da linguagem. Sendo a existência a ênfase dada ao ser humano que se auto supera e se compreende através da palavra, em torno desta última passa a constituir uma reflexão filosófica que vem revolucionar o século XIX, com Wittgenstein. Se, para Nietzsche, não existe verdade, e sim perspectivas, é pela linguagem que irá se manifestar toda esta multiplicidade perspectivística. Pois, segundo Wittgenstein, pela linguagem se revela o mundo como formas de vida e, através da forma pela qual a linguagem é utilizada, vai se descortinando o mundo.

${ }^{6}$ Cf. VALADIER, 1985, p. 247

${ }^{7}$ Cf. GIACOIA JÚNIOR, 2000, p. 60 
Diante destas três grandes tendências que a recepção do pensamento de Nietzsche dá margem, como desdobramento de suas intuições básicas, a aniquilação e a construção não são momentos separados mas constituem dois momentos de uma mesma realidade. Neste sentido, o suscitar de inúmeras inquietações do ser humano não ocorrem de forma esfacelada, mas formam um todo em momentos contínuos, em redes caóticas e, ao mesmo tempo, orgânicas, como é o caso da existência que se encontra no indivíduo que suscita a psicanálise, e esta, centrada na palavra, suscita a linguagem.

Constatamos, assim, como estes temas estão interconectados, mas não de maneira sistêmica e, sim, orgânica. O sistema conta com uma lógica, que, em Nietzsche, não é o caso, pois o que interconecta o pensamento dele é organicista vitalista, que perfaz justamente as passagem do aniquilar e do construir e vice-versa. Com isso, somos levados a constatar, com Gianni Vattimo, ${ }^{8}$ que a moralidade, por consistir na crença de que a ação humana é moral, é um erro fundamental. Há, um liame que perpassa todos os temas que constituem a filosofia de Nietzsche, capazes de suscitar sempre respostas a novos questionamentos. Por isso perguntamos: em que medida tais respostas e questionamentos, pelo viés do pensamento nietzschiano, tem satisfeito os anseios do ser humano atual e futuro?

\section{0 momento culminante: entre o presente e o futuro}

O pensamento de Nietzsche foi, muitas vezes, tomado de forma irrefletida e até leviana, como foi o caso da leitura feita pelos nazistas. Contudo, esse fato, longe de ser algo meramente do passado, continua a acontecer, e isto entre as instâncias mais diversas da sociedade, nos meios acadêmico, jurídico, político, jornalístico e, inclusive, midiático. $\mathrm{O}$ "modismo Nietzsche" persiste com toda a sua força. Porém, infelizmente, na maioria dos casos o autor é utilizado de maneira torpe, pois os que dele se utilizam têm como objetivo responder a alguma questão pontual e, para tanto, vasculham no emaranhado farmacêutico dos aforismos nietzschianos aquilo que melhor se adequa a seu diagnóstico, e não raro, o medicamento oferece apenas um efeito paliativo e, até, narcotizante.

Ante estas considerações, constatamos estar envolvidos numa sociedade enferma, atraída pela enfermidade do autor, procurando encontrar alguma receita de cura. É um caminho bastante arriscado, pois, num estilo como o de Nietzsche, em que a descontínua gama de fórmulas perfaz seu repertório, não é aconselhável tomar uma forma aleatoriamente, sem um conhecimento prévio das demais e, além disso, vendo entre todas as fórmulas, um liame diverso e anímico que a todas perpassa, constituindo um todo plural. Desse modo, o desconhecimento do conjunto da obra de Nietzsche, por aqueles que dele se utilizam, conduz a inúmeros equívocos.

${ }^{8}$ Cf. VATTIMO, 2002, p. 62-3 
O próprio estilo com o qual a obra fora concebida, facilmente se presta a isso. Contudo, como vimos seu próprio autor chamou a atenção quanto a isso. Mas, então, quem pode ler Nietzsche ja que seu acesso é tão difícil, incluindo inúmeros riscos? Eu responderia: todo aquele que cultiva o mínimo de bom senso que inclui honestidade intelectual, que o respeita em sua totalidade, realizando as devidas contextualizações, conhecendo os temas aos quais Nietzsche trata, como é o caso, por exemplo, do Cristianismo. Neste caso concreto cabe perguntar: até que ponto Nietzsche conhece verdadeiramente o Cristianismo ou de que tipo de Cristianismo ele trata. Expressões como "Deus está morto" (NIETZSCHE, GC, KSA, § 125, 1999, p.147), "[...] apenas a prática cristã, uma vida tal como a viveu aquele que morreu na cruz, é cristã" (NIETZSCHE, AC, KSA, § 39, 1999, p. 211), podem prestar-se a inúmeros equívocos, quando não devidamente depuradas. Como sua estilística é bastante fascinante e, até, enfeitiçadora, não raro, os que se aventuram a ler Nietzsche vacilam, sendo presas da teia de seu pensamento; de modo que, das questões às quais outrora se procurava responder, o que resulta é nada senão um emaranhar-se em uma multiplicidade caótica de dúvidas e incertezas.

Se hoje ainda persistem leituras apressadas e heterodoxas, então o que dizer do futuro? Em que medida a extemporaneidade de Nietzsche é capaz de lançar diagnósticos sobre o futuro? A busca irrecusável de sentido do ser humano contemporâneo pode ter em Nietzsche a segurança de, pelo menos, encontrar algumas pistas por onde caminhar? Será que o otimismo que, aparentemente, aponta o caminho do homem ao além do homem pela vontade de potência é capaz de ativamente cruzar a tormenta imposta pelo niilismo? O voluntarismo vitalista que o pensamento de Nietzsche aponta não parece gozar de tanto otimismo assim. Pois, ao mesmo tempo que Nietzsche aposta na potência do ser humano, de forma individual, buscando superar-se; essa mesma superação esbarra no sem sentido. Por isso, neste caminho trilhado pela vontade de potência não há nenhuma meta a alcançar que possibilite superar o niilismo, senão apenas não rebaixar-se passivamente a ele. O que Nietzsche procurou apresentar não é nada senão a disposição do ser humano frente ao niilismo, ou seja, como o ser humano deve portar-se diante do turbilhão inevitável do niilismo, sem a ele sucumbir passivamente. Mostra-se, contudo, ativo em meio às suas procelas, que se manifestam sobretudo, pelos processos de massificação resultantes de mecanismos sociais moralizantes, não podendo sucumbir a um individualismo solipsista, tal como Frederick Copleston apresenta ao enfatizar o caráter social da cultura. Como ele diz, "tentar restringir a cultura a certas camadas é desprezar a relação entre a cultura e a natureza humana, e tal tentativa envolve uma falsificação da cultura e uma errada compreensão do seu caráter social. ${ }^{9}$ " Contudo, essa disposição ativa, em

\footnotetext{
${ }^{9}$ Cf. COPLESTON, 1979, p. 276
} 
meio ao niilismo, não constitui uma saída frente a ele, não oferecendo otimismo, talvez um otimismo aparente, pois o encerra no caos mais radical, donde se deriva nada senão incerteza e pessimismo.

Mas, apesar disso, o que a filosofia de Nietzsche pode ensinar é a arte de rir, como um porvir alegre mais atroz e beligerante do que o existencial niilista. O rir se fundamenta sobre a arte do inovar, e sobre isso, Feiler, em sua leitura de Nietzsche diz que "[...] é sobre as bases do inovar, do mudar e do criar que Nietzsche pretende realizar seu projeto de transvaloração dos valores, ou seja, estabelecer valores sobre aquelas novas bases. É o peregrino Zaratustra, descendo da montanha a fim de partilhar os seus conhecimentos, como Jesus de Nazaré saindo de sua cidade natal a fim de dar início a sua missão. ${ }^{10,}$

\section{Considerações finais}

Nossa incursão pelas sendas nietzschianas, seja em seu estado da pesquisa atual, seja em sua forma de recepção no Brasil e no mundo, bem como em seu balanço entre presente e futuro, conduziu-nos a perceber o quanto sua pesquisa é ainda atual. Talvez essa atualidade e popularidade se mostre pela versatilidade do pensamento de Nietzsche: um pensamento sempre apto a responder a uma gama infindável de assuntos, razão pela qual seu pensamento tem sido alvo dos maiores mal-entendidos, comprometendo, inclusive, sua clareza e entendimento. Mas, além disso, seu uso irrefletido pode reverter-se numa arma mortífera, como o foi durante a Segunda Guerra Mundial.

Entre aquelas três formas que salientamos no primeiro capítulo sobre quanto ao modo do estudo de Nietzsche: o Nietzsche pelo Nietzsche, o Nietzsche como ferramenta e o Nietzsche aliado a problemas alheios a ele, somos inclinados a pensar que a segunda forma: o Nietzsche como ferramenta crítica é o que mais se tem desenvolvido nos últimos anos. Nietzsche tem sido tomado como ferramenta para inúmeros problemas, desde aqueles de cunho estritamente acadêmico, como em refletir sobre a desconstrução da concepção do sujeito moral, até aquelas questões mais corriqueiras do dia a dia, como em pensar as diversas expressões artísticas.

Pelos desdobramentos que vimos do pensamento de Nietzsche entre o existencialismo, a psicanálise e a filosofia da linguagem, se destaca a psicanálise. Cada vez mais cresce o número de interessados em Nietzsche para buscarem se autoanalisar. E, neste sentido, a filosofia de Nietzsche tem dado uma grande contribuição no sentido de pôr a descoberto inúmeros mecanismos inconscientes reprimidos pelos aparatos da sujeição da moral.

Assim, em se tratando da situação presente e futura quanto à pesquisa Nietzsche, somos levados a constatar uma popularidade muito

\footnotetext{
${ }^{10}$ Cf. FEILER, 2011, p. 98
} 
grande que parece se estender da atualidade para os tempos futuros. Os problemas que a extemporaneidade de Nietzsche alcançam ultrapassam os limites circunscritos pelo tempo presente.

Nietzsche pensou para além de seu tempo, como também até para além do nosso, razão pela qual sua leitura se torna ainda mais complexa. A cada epiciclo que é realizado no universo caótico do retorno um porvir é associado. O caos automaticamente nos lança ao porvir, por isso, mais uma vez, é impossível separar em Nietzsche os movimentos de aniquilação e de criação. Ambos constituem uma única realidade em faces que se complementam. Assim, pelo aniquilar e criar, o caos angustiante da existência presente aponta para o porvir rejubilante da vida futura.

No entanto, a grande questão que se coloca é: em que medida o caos pode apontar para um verdadeiro júbilo, já que o que se vislumbra não é nada senão o niilismo, frente ao qual não há nada a se fazer para transformálo em sentido? Por isso, talvez a grande contribuição de Nietzsche vá na direção de se investir numa postura que o ser humano cultive para não negar o niilismo, mas para não se resignar diante dele. Essa grandeza de alma, esse espírito livre, esse depender de um quantum de potência, fazem da filosofia de Nietzsche a arma mais poderosa para não sucumbir ao turbilhão niilista. Assim, toda a reação, da qual o ressentimento é o seu mais dileto rebento deve ser superada pela ação em que pela força se crie sempre novas possibilidades que apontem para o porvir. Não que este último elimine o caos niilista, mas, pelo menos, ofereça uma disposição ativa e criadora, quando tudo parece levar à submissão e inanição.

\section{Referências bibliográficas}

COPLESTON, Frederick. Friedrich Nietzsche: philosopher of culture. London: Burns, Oates \& Washbourne, 1979.

FEILER, Adilson Felicio. Nietzsche: sujeito moral, cultura cristã. Porto Alegre: Edipucrs, 2011.

GIACOIA JÚNIOR, Oswaldo. Nietzsche. São Paulo: Publifolha, 2000. . Nietzsche como psicólogo. São Leopoldo: Editora Unisinos, 2001.

LÖWITH, Karl. Nietzsche. Stuttgart: J. B. Metzlersche Verlagsbunchhandlung, 1987.

MARTON, Scarlett. Nietzche:das forças cósmicas aos valores humanos. São Paulo: Brasiliense, 1990.

NIETZSCHE, F. W. Der Antichrist. In: COLLI, von Giorgio; MONTINARI, Mazzino (Herausgegeben). Kritische Studienausgabe in 15 Bänden. München: Taschenbuch Verlag de Gruyter, 1999. Bd. 6. . Nachgelassene fragmente: herbst 1887 bis märz 1888. In: COLLI, von Giorgio; MONTINARI, Mazzino (Herausgegeben). Achte Abteilung. Berlin: Walter de Gruyter, 1970. Bd. 2. 
Nachgelassene Fragmente, nr. 9 [154]. In: Sämtliche Werke. Ed. G. Colli und M. Montinari. Berlin, New York, München, 1980, vol. 12, p. 426s.

VALADIER, Paul. Nietzsche et la critique du christianisme. Paris: Du Cerf, 1974.

Nietzsche y el cristianismo. Seminários de FILOSOFIA, Paris, Centro Sèvres, Universidad Católica de Lyon, n. 7, p. 11-29,1994.

VATTIMO, Gianni. Nietzsche: an introduction. London: The Atholene Press, 2002. 